Article

\title{
Cyber-Cultural History: Some Initial Steps toward a Cultural History of Digital Networking
}

\section{Federico Mazzini}

Dipartimento di Scienze Storiche, Geografiche e dell'Antichità, Università di Padova, Via del Vescovado, 3035141 Padova, Italy; E-Mails: federico.mazzini6@gmail.com; federico.mazzini@unipd.it; Tel.: +39-329-542-9651

Received: 17 March 2014; in revised form: 14 May 2014 / Accepted: 14 May 2014 /

Published: 20 May 2014

\begin{abstract}
Too much in the present to be legitimately regarded as "history", yet too important to be ignored by scholars, the cultural history of digital networking remains a largely unexplored field of study. The present article seeks to connect the reasons for this lack of interest in the subject to the difficulties which historians face when approaching it. By piecing together the fragments of a history that for the most part still awaits being written-yet not always by taking historical-cultural works as a starting point-the author suggests some key moments, crucial themes, critical points and possible future developments.
\end{abstract}

Keywords: cultural history; media history; computer history; digital networking

\section{Introduction}

"There is no shortage of questions"-Marc A. Smith wrote in a book he edited on Communities in Cyberspace in 1999- "but we lack a historical record of the transformations of social cyberspaces just at the point when network interaction media are being widely adopted" [1]. With the launch of "Web 2.0", the field for which only a poor historical record existed, according to the sociologist, has itself become part of history. Following the emergence of social networks as the main gateway to “cyberspace”, digital communication has not only spread far and wide, but has also engendered new modes of interaction (between human beings, between human beings and machines, between machines), of a sort which would have been quite inconceivable only a few years before. As a consequence, there has been a flourish of cultural studies of the Web. Yet, to this day, historical-cultural studies of the subject remain relatively rare: the four volumes edited by Daniel Bell in 2006 on 
Cybercultures: Critical Concepts in Media and Cultural Studies, include only three contributions from historians, of which only one (that by Paul Edwards) adopts a historical-cultural approach [2].

One first possible explanation for historians' reluctance to approach networked cultures may be found in the evolution of the technological means that ensure digital communication. Much of the technological development of the Internet has come from users or groups of users who, in an attempt to make the networks more suited to their needs, created practices and processes that soon came to enjoy wide popularity. The best-known example is probably electronic mail, which emerged as an "improper” use of the first digital network, ARPANET. Independently introduced by a small group of programmers back in 1971, it came to account, within a few years, for most of the traffic in US universities with online access [3]. Electronic mail turned a tool originally developed as means of sharing hardware and software resources into a means for interpersonal communication, a way of connecting people rather than machines. The computer, which up until then had chiefly been employed as a calculator or a means to control other machines, underwent a process that, within a decade or so, was destined to turn it into "information technology".

Certainly, the desire on the part of "consumer-users" to modify a standard technological object in order to adapt it to their needs or to test their technological prowess is not limited to digital networks or computers [4]: ever since the early 20th century, popular science magazines in the US published guidelines for modifying household appliances and using them in ways which their inventors and sellers had not foreseen. To give just one example, the first gasoline-powered lawnmower was invented in 1919 by applying a washing-machine engine to a mechanical lawnmower [5]. The idea of altering industrial consumer items such as the radio [6], Ford cars and AT\&T devices [7] gave rise to a community of users that directly foreshadowed the groups of enthusiasts who influenced-and in some cases spearheaded-the development of consumer ICT (Information and Communication Technologies) and digital cultures. As early as 1986, Eric Von Hippel identified the "lead user" (i.e., the user who seeks to modify a standard device so as to adapt it to his needs) as one of the driving forces behind the conceptual and technological innovation of industrial and consumer products, especially in the high-tech field [8].

What distinguishes the spread of a digital product from that of other technologies is the lack of infrastructural limits and of any pre-distribution procedure of evaluation on the part of those supplying the infrastructures. To reach the general public, the gasoline-powered lawnmower had to be endorsed by an industrial actor who recognized its commercial potential and ensured its production and distribution. Electronic mail, by contrast, spread only by virtue of its functionality and popularity among its originally very limited user base. Facebook, a way of using the Web that revolutionized the approach to the Internet for millions of people, gained prominence within just a handful of years, starting from a website exclusively designed for Harvard students in 2004. By 2008, the platform had reached 100 million users [9]. In April 2014, the company, by then on the stock market, boasted over a billion active users [10].

The decentralized nature of digital networks-including those in theory controlled by academic or military authorities, such as ARPANET-fosters a degree of innovation, transformation and adoption of new practices unmatched by any other technology. By this I do not mean to say that online innovation is necessarily more democratic that that brought about by research centers and industrial companies [11], or that it knows no financial, legal or advertising limits. Rather, I simply mean to 
stress the speed at which technocultural changes can take place through a non-material technological medium such as software code. As Geert Lovink has noted, "there is no doubt that technology such as the Internet lives on the principle of permanent change. The 'tyranny of the new' rules (...)” [12].

This process of acceleration, moreover, tends to grow exponentially. If each user is a potential innovator, and if innovators have the previously unthinkable opportunity to witness other users-innovators adopting their creations, then the broadening of the user base (an apparently unflagging process since the launching of ARPANET in 1969) will increase the transformation of the technology and its mode of fruition. These dynamics have been fully understood and considerably encouraged-in terms of technical as well as economic efficiency-by the people who have defined and promoted what is known as the "open source” practice [13] ("given enough eyeballs every bug is shallow," states Linus's Law, as formulated by Eric Raymond) [14,15]. With growing computer literacy rates and the spread of user-friendly interfaces, more and more users now have the chance of becoming "lead users", thereby meeting increasingly varied and specific requirements through their creativeness, on the basis of a pre-existent network.

\section{Tyrannized by the New: Cultural History and Digital Networks}

As may easily be imagined, this accelerated transformation raises quite a few problems for anyone wishing to trace a cultural history of digital networking; these are its self-imposed chronological limits. Let us imagine we were to write a history of digital networking focusing on so-called Web 1.0, the "read only" Web-where the possibility of adding content was often limited to the few individuals capable of modifying HTML script. The beginning of this history may be taken to be 1991, with the publication of the first website by Tim Bernes-Lee [16], or 1993, with the release of the first graphic browser, Mosaic [17]. Hypertext and a user interface no longer based on text commands (along, of course, with elements independent of the network, such as the spread of personal computers and increased media attention) opened the doors of "cyberspace” to a broad public of non-specialists, diversifying its functions. The end of this hypothetical history may be set as 2006, when Times magazine chose "You" as Person of the Year, celebrating a change in the mode of fruition of the tool (so-called Web 2.0) [18], which specialists in the sector had already noted and discussed in the early 2000s [19].

There is no doubt that the moment one starts talking of Web 3.0, or "Semantic Web", Web 1.0 represents a historically completed process worthy of historiographical attention-if for no other reason than its importance in contemporary society. Yet, defining 2006 as a legitimate object of investigation is not something the historian can do without feeling daringly experimental or dangerously on the fringes of his area of expertise [20]. Because of the frantic succession of techno-cultural events, many excellent texts are perceived by the reader to be out of date only a short time after their publication: from the point of view of historical narrative, which rests on the authority of the writer and the assumption that he or she knows the subject in the greatest detail, it is difficult to accept the idea that only a few years later an informed reader will have a better picture of a given process. It is hardly surprising, therefore, that a fair share of the historical-cultural accounts mentioned in what follows have been written by specialists in other sectors, as premises or side notes to sociological, anthropological or media studies. 
The difficulties which the discipline understandably faces in adapting itself to the compressed time frame for networks are not the only obstacle in the way of a cultural history of networking. Even some crucial aspects of digital networking which emerged before the 1990s have yet to receive adequate historiographical treatment. One example is "hacker culture," a phenomenon whose central importance in relation to the development of the Web as we know it today is widely acknowledged [21], and which will be referred to again and again in this article. The historical reconstruction most often quoted in cultural studies on hacking was provided by journalist Steven Levy in 1984 [22]. For the more recent developments of the phenomenon, scholars often draw upon the memories of Eric Raymond, a genuine hacker celebrity who published his most frequently quoted book, The Cathedral and the Bazaar in 1999 [14]. Both texts overemphasize the role played by a few stereotypical and "heroic" individuals, for explicit celebratory purposes (besides, the authors make no claim to be writing as historians). Still, these popular memorials - expressions of hacker culture rather than analyses of it - are quoted in some of the leading studies on digital culture for want of better alternatives.

I believe that the reason for this deficiency lies first of all in the immaterial quality of digital networking. As soon as it leaves the halls of the Massachussets Institute of Technology (where the word "hacker" was probably used for the first time in relation to computing) [23,24], a hypothetical cultural history of hacking is faced with countless groups and individuals who describe themselves as hackers, often with very different aims, practices and values-a difficulty well known to anyone researching the history of political groups or ideologies. What is new in the case of digital networking, is the immaterial quality of the social actors and the weakness of the links that hold "virtual communities" together. Like phreakers before them, and like most members of contemporary online communities, hackers conceal their identity behind a nickname-or, as is more often the case, several nicknames. Establishing who may have stated what, and when, in a world based on immaterial identities, in which anyone can change their name at any time or even adopt someone else's, is a very difficult task indeed. With few exceptions, virtual communities themselves have shifting borders that can hardly be defined with any degree of exactness: members will come and leave, and the nature, reasons and duration of their involvement is often impossible to pin down, at least according to the standards of precision which history is usually expected to conform.

Yet, to keep to the example just provided, there can be no doubt that a closer historical investigation of hacker culture is called for today. The link between this culture and American counterculture has been emphasized by several authors, but rarely explored. The dominant narrative, which quite rightly stresses the academic origin of hacking, on the one hand fails to examine the way in which academic culture has actually influenced hacker culture (e.g., the "open” system of collaboration, peer-recognition as the reward for one's work); on the other, it ignores coeval cultural phenomena, such as the emergence of youth culture and the consumer society boom. The "phreaking” phenomenon, which developed almost at the same time among high-school students and telephone technology enthusiasts, shows striking similarities with hacker culture, although—at least originally—it was far more closely connected to the countercultural Yippie movement than to the academic culture of MIT [25]. What is still missing is an attempt to examine the phenomenon within the context of American culture as a whole, in such a way as to illustrate its relation to American "voluntaristic" individualism [26], explain its almost immediate association with anti-authoritarian libertarianism, define the (very early and close) relation between hacker culture and Hollywood pop culture and, more generally, provide a 
historical definition of hacker culture as a youth (counter) culture [27]. An investigation of this sort is crucial in order to grasp the nature of contemporary digital cultures, the form taken by networks, and the online behavior of people who have nothing to do with hacking. Fragments of this enquiry are scattered across various studies, but - to the best of my knowledge-have never been made the object of a specific historical monograph.

Possibly even more disturbing, from a historian's perspective, is the issue of the sources. Scholars of so-called digital history have long been wondering about the fate of historical sources in the digital era, the difficulty of ascertaining their authenticity, the ease with which they can be manipulated, and the problem of how to preserve them [28]. First of all, there is the quandary of the number of sources and of the inevitably partial and purely indicative nature of any historical account of the networks, even when limited to a single aspect of the topic or to a relatively narrow chronological framework. Let us take Usenet as an example, one of the first digital networks to have been made available to a non-academic public. Established by two Duke University students in 1979, Usenet enjoyed great popularity among users of the UNIX operating system as a more affordable and more easily accessible alternative to ARPANET. Usenet was structured around thematic newsgroups which users could "subscribe to" in order to receive real-time updates: one would expect this to make it easier for the researcher navigate the information required. The text files circulated on Usenet have been preserved and may be viewed through Google Groups [29] or, more easily, on the Usenet Archive, a site set up by an early user, Craig J. Stadler. However, the files offered by Google amount to at least 700 million; 80 million files are already accessible within Stadler's Usenet Archive, while another 200 million are about to be published in it [30]. A qualitative analysis of such an amount of data might require years. It is extremely difficult to define any itinerary in this multitude of heterogeneous texts [31,32], or indeed to measure the significance of the examples selected: "Size and complexity both call for much more humility, since no single chapter, no single book, can really address or analyze the whole Web. (...) Of course, criticism of all kinds depends on the critic's discretion, on a reasoned and reasonable balance struck between the representative and the anomalous. But the sheer size and diversity of the World Wide Web suggests that in this case, balance might be a rank impossibility.” [33]. There is the risk-already faced by many non-specialist publications and not entirely absent from academic ones either-that the over-abundance of information on the "popular" use of the tool might lead to the writing of a more manageable history of "great" events and "great" men: the history of Mark Zuckerberg rather than Facebook users.

Given the immaterial nature of these sources, there is no guarantee that the corpus will be in any way complete. Indeed, in the case of a system such as Usenet, in which files would be automatically deleted every so often in order to free up more memory, it is almost certain that much of the communication has been lost. Another example might be the Bulletin Board System (BBS), one of the most popular forms of digital networking among PC users in the 1980s and early 1990s. Each BBS was linked to a phone number, which the user had to dial through a modem, in such a way as to connect to servers hosting "digital boards" devoted to specific topics. The largest BBS archive I have been able to find, TextFiles, has been created by an early BBS enthusiast, Jason Scott. It includes over 58,000 files—no doubt just a fraction of all the messages exchanged between 1980 and 1995.

If not for aficionados such as Scott and Stadler, or projects such as that launched by Google, even these partial traces of early digital culture would remain out of bounds for historians and would be 
destined to disappear in the long run. One can only be thankful to those who have chosen to invest time and money in endeavors of this kind, particularly private individuals. Yet the fact that these archives of immaterial sources are set up and managed by private citizens is in itself a disincentive which may help account for cultural historians' reluctance to engage with the subject. Leaving aside the problem of the creation of complete and consistent corpora of digital sources-which institutional actors would also have to face- the central question is how to archive the sources and preserve them. In the cases just referred to, what are missing are professional archivists to help order the vast amount of material and, most importantly, offer the researcher some reassurance regarding its authenticity, thereby freeing him or her from the obligation of having to verify sources that are so easily modifiable. Yet what proves even more confusing for the historian, perhaps, is the absence of an institution which may guarantee the possibility to continued access to the sources, in the same order, in future years. What comes into play here is the durability of historical writing. If in a year's time all the links I have quoted so far are no longer accessible, this will diminish the value of the article, or at any rate make it less consistent with the criteria set by the discipline. Should Stadler or Scott choose to quit their hobby for any reason, what will be lost along with the sources is some of the credibility of any piece of writing based on them. We may be reasonably sure that Google will remain online for many years to come, yet it is far from certain that it will keep up its interest in archival work, or that its mode of archiving and the motivations behind it will coincide with the priority of academic research. The very mode of citation of online material that is currently in use-whereby along with a website address the researcher will give the date of the last day on which he or she accessed it —on the one hand is based on a classification and retrieval criterion, the Web link, which is hardly suited to paper publishing (and the academic predilection for this format is all too well known); on the other hand, it adds to the system of verification of the sources and creation of authority a subjective and aleatory element ("I have seen it, it may still be there") which is largely unsatisfactory. This may be the reason why we continue to exchange bibliographical references of articles from JSTOR as though we had read them on paper, often without providing a link, even though we know that in all likelihood our readers will access the same online service if they wish to follow up the reference.

These problems obviously concern all online sources. Yet in the case of a cultural history of digital networking, the issue becomes a particularly pressing one, given that this kind of research-unlike an investigation into the technological or intellectual development of the tool—will largely be based on exclusively digital sources. A digitalized source has a "real" material counterpart. If the digitalization process has caused some distortions, or if the source disappears from the site through which it was first accessed, it will still be possible in most cases to go back to the original [34]. This is not the case with a digital source, one specifically created in an electronic format and only accessible online.

Worse still, even aside from the issue of the preservation of the sources, what is found online in most cases is a "finished" product. The exclusively digital process of creative production of the source, which is crucial in order to grasp its cultural significance, is usually unattested: "Indeed, much of what has in the past provided history, the rough drafts, scribbled notes, scratched out lines, disappears with the electrons and pixels we readily manipulate to erase traces of the creative process in pursuit of an ideal end product” [35].

Moreover, if a source was originally developed in an electronic format, this makes it very difficult to detect any possible manipulation. In the case of a text file, all that it takes to create a technically 
perfect forgery is a keyboard and text editor. In the case of audio-visual material, the software employed may be more sophisticated, but not to the point of requiring the work of digital editing specialists. The best guarantee against forgery (itself a rather ambiguous term in the digital era) for anyone conducting research on Usenet lies in the fact that presumably no one has any interest in fabricating texts - a hardly reassuring guarantee, no doubt, and one which does not take account of unintentional manipulation or what may have been regarded as perfectly legitimate alterations on the part of their authors. A useful example is provided here by Requests for Comments. RFCs are messages which started spreading on ARPANET in 1969. They were used by researchers to openly and informally discuss the main technical aspects of the network and its lines of development, to set its "best practices" and technical standards. The series of RFCs still continues under the responsibility of the Internet Society: as I am writing this, 7,101 RFCs were published. This corpus too, however, despite its constant monitoring on the part of the aforementioned association and its great historical and cultural relevance, is rather problematic from a research perspective. As Lisa Gitelman explains, the first 600 RFCs were lost with the development of the software and were "restored" in the late 1990s. The missing documents were added to the series through the RFC software that was in use in the 90s, but which was unknown in the beginning of the 70s: these sources have a completely different appearance from the original ones. "Can these early RFCs, now digitized or redigitized, really be considered identical with the original RFCs” ([30], p. 121) even assuming we can trust the accuracy of the transcription? The question posed by Gitelman is particularly important for cultural history, where data is sought for in the signified as much as in the signifier, in content as much as in form.

Regrettably, I believe there is no way to solve this problem. "Redigitized” RFCs (but the same also applies to Usenet messages or BBSes) are all that we have-digital traces of a digital past. The study of digital cultures increases the main difficulty faced by the historian of modernity (namely, creating coherent and representative narratives out of an over-abundant reservoir of information). At the same time, it raises the kind of challenges which are usually associated with the study of other historical periods (such as the difficulty in attributing or dating sources, and the need to produce a qualitative assessment of each source in order to verify its authenticity). Historians will undoubtedly develop methods to partially mitigate the consequences of the immateriality of the sources: through shared metadata standards, a more focused archival effort, and an improved system of citation of online resources. In time, they will probably more fully embrace the new communication methods, making full use of the hypertext and maybe creating companion websites that will ensure the durability of the sources that sustain their specific writings.

Applying old tools to new objects might not be enough though. In many cases-as Steve Jones writes - "it is possible that when it comes to Internet research, our methods are not scalable” ([35], p. 25) and that the discipline will have to redefine its methods as much as its standards in relation to its object of enquiry. It will probably have to accept to some degree the uncertainty that comes with immateriality and the weak, ephemeral authority that can be exercised over such a dynamic and ever-changing technocultural phenomenon. Over the following pages, I will endeavor to provide a few suggestions with regard to this possible process of redefinition and to identify the key points of a cultural history of digital networking as they appear in the few major studies that approached the subject. The "fragments" I will present will not, if put together, form the image of an organic field of study that may be called "cultural history of digital networking.” They come from works that have different aims 
and often different disciplinary frameworks, and in examining them together, I am aware of the risks involved in going beyond the intentions of their authors, as well of the inevitable subjectivity involved in every review. What these studies have in common, in my view, is the need to historicize some cultural aspects of digital interconnectivity in order to illuminate their particular object of study. In doing so, they suggest different themes and paths related to the culture of interconnectivity that can, in my opinion and in the near future, be explored from a cultural-historical perspective.

\section{Fragments of a Cultural History of Networking}

As one may imagine, all reconstructions of the technological development of the Web include aspects related to cultural and social history. After the studies conducted by Pinch, Bijker and others [36,37] and the research on "technoculture" [38] few publications on the history of technology have failed to take account of the cultural context of technological development. This is particularly true in the case of a technology such as digital networking, where-as previously noted — the user/innovator plays a primary role.

While always acknowledging the active role of users, scholars who have reconstructed the history of ARPANET tend to focus on the contribution made by military and academic cultures to the definition of the network and its main features (many of which have survived to this day, as in the case of email and TCP/IP protocols). One of the first and most authoritative reconstructions of the origins of the Internet, Janet Abbate's Inventing the Internet, sets out from the claim that it seeks "to cross the divide that exists between narratives of production and narratives of use" and to show that the "social dynamics that we associate with the use of networks also came into play during their creation, and that users are not necessarily just 'consumers' of a technology but can take an active part in defining its features” [39]. The agency of users, while constituting the real driving force in terms of innovation according to Abbate, nonetheless had to negotiate its aims with those funding the research (the Department of Defense) or supervising it (the Defense Advanced Research Projects Agency_DARPA—and the individual academic institutions connected to the network).

At least from the time of Vannevar Bush's report Science: The Endless Frontier (1945), in the public funding of scientific research in the U.S. substantial decision-making power was left to the academic recipients [40], an element which helps explain why the practices and values expressed on ARPANET were closer to university culture than military culture. Thomas Hughes stresses the role played by a management capable of granting its subordinates (be they private institutions and companies, or individuals), considerable freedom in the pursuit of what ultimately remained academic goals. J.C.R. Licklider, the head of the ARPANET project between 1962 and 1964, is a central figure in Hughes's narrative; changes in the use of the network are largely connected to his vision of a symbiosis between man and the computer, and to the ability of the DARPA management to create a class of technicians who shared this vision. Hughes identifies the roots of the decentralized nature of the network not so much in the presence of communities of self-organized users, as in the "traditional values of academic research, such as freedom of inquiry and dissemination of information” [41], in which the managers of the ARPANET project were steeped. Likewise, Detti and Lauricella give much emphasis to Licklider's writing — especially The Computer as a Communication Device (1968)—since it foreshadowed the future function of networking as a means for interpersonal connection. According 
to the two scholars, the contribution made by users is only one aspect of the development of the tool, which is often blown out of proportion: even the birth of electronic mail, often invoked as an example of the "grassroots" nature of digital innovation, owes as much to the approval and enthusiasm shown by managers as it does to the inventiveness of the users who created and perfected the software behind it [3].

Studies analyzing the later phases in the development of digital networking often place more emphasis of the agency of end-users. Manuel Castells argues that the "Internet Culture" comprises four layers, connected to the different cultures which have influenced the development of the tool and its uses [42]. First of all-rather predictably-we find academic/scientific culture, which Castells describes as "techno-meritocratic," based on the values of technological discovery, peer-review as a means to mark the success of scientific pursuits, the free exchange of results attained through group research, and the role played by charismatic coordinators who exercise control over the resources and access to the technologies.

All these features, except for the last, are also common to hacker culture. Castells points out that hackers "are not what the media say they are” ([42], p. 41) (namely digital pirates and cyberspace criminals). Rather, he argues, they are the representatives of a culture based on the idea of freedom: the freedom to access computer codes and systems, the freedom to alter them as one wishes. This is a highly meritocratic gift-culture [43], in which the reputation of each (usually anonymous) member is grounded on their contribution to shared projects. Castells draws upon the description of hacker culture provided by Himanen, Raymond and Levy, and significantly developed by some more recent anthropological case studies [44,45]. The originality of Castells's contribution lies on the one hand in its attempt to connect hacker practices to the development of the Internet as a cultural object [46], and on the other in its observation that the world of hackers has historically been far more diverse than what the descriptions provided by Raymond, Levy and other authors would appear to suggest. Indeed, this world encompasses a range of different subcultures (including that of "digital pirates"), each of which is of anthropological and historical interest.

A third layer, which has possibly been investigated even less from a historical perspective [47], is constituted by what Castells describes as "virtual communitarians": all those users who, while having no real computer expertise or possibility to further develop the technology, have nonetheless influenced the way in which the resource is used, often in radical and enduring ways. The first historical expressions of this composite category may be traced back to the American counterculture of the 1960s, to the spirit of the communes and the utopian idea of the computer as a means to self-liberation. These origins are important not just in relation to the technological factor, but for the very way in which millions of people experience the Internet today: "The culture of first-generation users, with its utopian, communal and libertarian undercurrents, shaped the Net in two opposite directions," Castells notes in The Rise of the Information Society. On the one hand, it has fostered a particular kind of digital activism and idealism "that looks with distrust at the commercialization of the network, and watches with apprehension how the realization of the dream of generalized communication for the people brings with it the limits and misery of humankind as it is.” Today this activism finds expression through a whole gamut of associations, such as the Electronic Frontier Foundation, Wikileaks and the F/OSS movement. On the other hand, the approach adopted by first-generation users stands at the basis of the modes of communication and exchange that are often established through digital networking 
(especially since the rise of Web 2.0): "what remains from the countercultural origins of the network is the informality and self-directedness of communication, the idea that many contribute to many, and yet each one has her own voice and expects an individualized answer.” [48].

The sociologist identifies two features which have defined every "virtual" community from the beginning: the emphasis on censorship-free horizontal communication and "self-directed networking" ,that is to say the possibility for each user to join a network that matches their specific interests and needs, or to create such a network and make it available to others if it does not yet exist. "From the primitive 1980's BBSs to the most sophisticated interactive systems of the turn of the century, self-publishing, self-organizing, and self-networking constitute a pattern of behavior that permeates the Internet, and diffuses from the Internet to the entire social realm.” ([42], p. 55). To verify this claim, which may come across as a dangerously peremptory one, I believe it is necessary to acquire a broader knowledge of online communities and their history. The contemporary development of the Web, for instance, would appear to suggest that the last constitutive layer of Internet culture according to Castells, namely entrepreneurial culture, is at least partly gaining control of self-networking, since it is defining the structures and forms of online self-expression. The success of standardized and carefully regulated platforms such as Facebook, Google+ or indeed Wikipedia poses a limit to users' freedom of expression and self-publishing and self-organizing possibilities; hence, it is inevitably altering some of the key features of digital culture. The use of nicknames, common to both hacker culture and the culture of virtual communitarians, is ill suited, for example, to the commercialization of personal data which is typical of social networks.

Castells focuses on the entrepreneurial culture of the Silicon Valley in the 1990s (the profusion of start-ups that "made money out of ideas" and out which giants such as Google, Sun Microsystems and eBay later emerged) - a fresh, multi-ethnic culture which soon became global. But a number of different companies and entrepreneurial cultures, not mentioned in Internet Galaxy, have been involved in the development of the Internet right from the start: BBN (Bolt, Beranek, and Newman), for instance, developed much of the hardware for early ARPANET, while various companies (including both traditional ones, such as IBM, and initially "countercultural” ones, such as Apple) turned the PC into a consumer item, thereby laying the foundations for the mass spread of digital networking. Castells's fourfold division, while not immune to criticism and highly ideal-typical [49], nonetheless provides a good starting point for future research on the collective actors in the cultural history of networks.

A different point of departure may be found in Paul Edwards's The Closed World. Computers and the Politics of Discourse in Cold War America [50], a study that without focusing on networking technologies directly still proves fundamental for understanding the context in which these technologies developed. Edwards's aim is to overcome the traditional division between intellectual history on the one hand (from Leibniz's rationalism to Weiner's cybernetics and cognitive psychology) and the history of computational technology on the other (from the abacus to the microprocessor), in order to present the history of the computer as a metaphor within the Cold War discourse (understood in Foucauldian terms). By borrowing the notion of "closed world" from literary criticism, Edwards argues that the computer (both as a tool and as an idea) served as "support" (again in the Foucauldian sense of the term) for the system of power/knowledge which characterized American politics and culture between the aftermath of the war and the Reagan administration: "closed world politics shaped 
nascent computer technology, while computers supported and structured the emerging ideologies, institutions, language, and experience of closed world politics.” ([50], p. 99). One of the main examples adduced by Edwards is that of the Semi-Automatic Ground Environment (SAGE), the computerized radar surveillance and automated response system for missile threats inaugurated in 1957. Against the backdrop of the panic caused by the loss of U.S. monopoly on nuclear weapons, SAGE offered a venue for the negotiation of technological choices (the digital computer instead of the analogical, data transmission through telephone lines) and military choices (a centralized and automated system of military response, as opposed to the traditional decentralization of the command system in a war scenario) on the part of various authorities (different sectors of the army, the scientists in charge of developing the project, the Eisenhower administration). SAGE also led to the emergence of a new political iconography, whereby the computer came to be seen as the best way of ensuring the "scientific" management of politics and war. SAGE was never actually used as a defense system: the introduction of intercontinental ballistic missiles very soon made the system obsolete. However, SAGE functioned as a "support" for the closed world discourse: the idea of centralized and computerized control, along with the utopia of a scientifically managed world rendered immune to external threats, was to emerge prominently once more with the Vietnam War [51] and Reagan's plans for a space-based missile defense system (the Strategic Defense Initiative-SDI, 1983). Studies on artificial intelligence, the birth of cybernetics, game theory, cognitive psychology and the rise of the “cyborg” in popular culture are all elements which Edwards examines in detail and brings together under the label of "cyborg discourse," as a corollary of the closed world ideology which projected onto the general population the utopia of automated and scientific control ensured by a perfect symbiosis between man and machine. "The closed world, with its mathematical models, tactical simulations, and electronic battlefields, represents the form of politics and war for brains seen as computers and minds conceived as information processors.” ([50], p. 273).

There are two main reasons why it is useful to link Edwards's pioneering work to the cultural history of digital networking. First of all, this would further enrich the complex picture painted by Edwards, by adding an element which the author only focuses on in the final pages of his work, when presenting the birth of the World Wide Web (a decentralized, user-driven resource that is difficult to control even for its developers) as a symbolic counterpart to-and outcome of - the closed world. However, as previously noted, decentralized and user-driven digital networks had been in existence long before the invention of the World Wide Web. Much like SAGE, Igloo White or the SDI, the Web was initially conceived as a military project: an "open” system funded and made possible by the very same political and academic actors who, in other fields, were developing the "closed" technologies of centralized control. For instance, Edwards quite rightly describes Licklider as the main promoter of the study of artificial intelligence and as a rabid supporter of the cyborg discourse in the military field. However, Edwards ignores what is arguably Licklider's most important achievement, namely the ARPANET project, from which the Internet was to develop. Digital networking first became popular among non-specialists precisely in the 1980s, in the era of Reagan's “Cold War 2.” Edwards's book, however, defines a clear cultural context within which to situate the emergence and development of digital networking, thus providing a crucial point of reference. His distinctly Foucauldian interest in dominant discourse helps to define the rise of decentralized networks as a "unique," if not antagonistic, event in relation to technological pursuits in the Cold War and sets on the stage for other crucial 
aspects of American society (such as individualist libertarianism, countercultural protests, and the idea of the technological frontier as a genuinely progressive mission rather than simply an anti-Russian endeavor) to be studied.

Secondly, Edwards's work shows the importance of moving beyond conventional categories and associations when examining the history of computer technology - even beyond the history of the “social construction” of technology promoted by Bijker and Pinch. In Edwards's words, it is a matter of including the "technological construction" of society within this historical narrative, in such a way as to describe a dynamic process in which culture (or cultures) and technologies influence one another, negotiating positions of power/knowledge that, once dominant, come to affect a whole range of cultural fields. Without a doubt, Edwards's book suffers from the limits of all Foucauldian studies, starting from the tendency to overlook forms of resistance or divergence. Still, I believe that the idea of the "technological construction" of society and cultures constitutes a necessary starting point for any explicitly cultural history of networking. To mention only one example which I consider of the highest importance and contemporary relevance, let us think here of the cultural history of the concept of "open source" (from academic institutions to hacker cultures and the Web), which now appears to be transcending cyberspace and influencing various other aspects of Western culture, through heterogeneous phenomena such as crowd sourcing, open access, crowd funding and crowd governance. I believe that the origins of this "open world" chronologically overlap with those of Edwards's “closed world,” although this in no way undermines the validity of Edwards's account.

A third possible starting point is provided by Charlie Gere’s book Digital Culture. Gere's definition of "digital" is not limited to the technical meaning of the term ("data in the form of discrete elements"), but encompasses "the whole panoply of virtual simulacra, instantaneous communication, ubiquitous media and global connectivity that constitutes much of our contemporary experience. (...) From this it is possible to propose the existence of a distinctive digital culture, in that the term digital can stand for a particular way of life of a group or groups of people at a certain period in history” [52]. The breadth of the term enables Gere to trace the first expressions of digital culture back to the 19th century, to the division of labor into "discrete parts," which was suggested by Adam Smith, formalized by Taylor, and applied by Ford. The phenomenon is viewed in relation to the first attempts to create programmable machines (e.g., the Jacquard loom) and computational ones (e.g., the Difference and Analytical Engines). Gere describes the period between World War II and the end of the Cold War, which he refers to as the "cybernetic era," in very much the same terms as Edwards: cybernetics, game theory, information theory and technowar reveal an attempt to break down social phenomena into "discrete" parts which may be precisely defined and analyzed in their future developments and mutual interactions - a desire for control stemming from the threat of a nuclear holocaust. "Thus our current digital landscape has been broadly shaped by the informational needs of capitalism and its drive to abstraction, and more specifically by the calculative and cryptological needs of the Second World War and the security concerns of the Cold War.” ([52], p. 202). The very issues addressed by politicians and academics during the Cold War were also faced by the artistic avant-garde and countercultural political movements. The answers provided here were different, yet equally centered on the problems of interrelation, attention and communication in a world brought together by communication technologies, yet at the same time divided into two opposing blocks. According to Gere, the multimedia and interactive experiments carried out by John Cash, the Fluxus group and the OuLiPo, just like the early 
expressions of computer art, not only foreshadowed the (intellectual and multimedia) forms of contemporary digital media but actually spawned them. While this claim ought to be verified in the light of more detailed studies, the link that Gere draws between computer technology and digital networking on the one hand, and the artistic avant-garde on the other, is a fruitful one that provides an interesting counterpart to the idea of cyborg discourse described in Closed World. What is also interesting is Gere's account of what he terms the "digital counterculture," which first emerged in California in the 1960s and 1970s. Here "the fortuitous proximity of acid and silicon brought together new technology and counter-cultural thinking and created the circumstances that produced the Personal Computer and by extension much of current digital culture” ([52], p. 123). Californian counterculture brought about a semantic redefinition of computer technologies (including digital networking): from symbols of technocracy to a means of self-fulfillment and way of revolutionizing social relations. The effects of this process_-first officially described in Ted Nelson's book Computer Lib/Dream Machines (1974) and made possible by the spread of personal computers-have become evident in the considerations put forward by academics as much as by activists and political parties with regard to the role of the Internet as a tool for participative democracy, and more recently in the debate on "Net neutrality" as a precondition for preserving this kind of democracy. Gere's book, however, offers a different perspective: in tracing the development of "cyberidealism” in the 1980s and 1990s, it illustrates how some of the features of the digital counterculture and of many hacker cultures have merged with neoliberal ideas, through a process of absorption of the revolutionary drive of the 1960s and 1970s which is not limited, of course, to digital cultures. The ideal of decentralized power, distrust towards any form of government or bureaucracy, and the praise of individual personal freedom and enterprise are all crucial features of "digital culture" which link it to neoliberal values-in some cases, such as that of Wired (below), to the point of making the two coincide. Again, the nature of these connections ought to be examined in greater detail, yet it is useful to view "digital culture" in the light of the contradictions of American libertarianism and individualism—national traits that have spread globally because of the very nature of the Web.

The notions of "digital culture” (Gere) and "Internet Culture” (Castells) are no doubt problematic, since they seek to pin down a culture which first emerged in the United States yet developed not in one specific place but as a means of communication. Some of the cultural features which Gere and Castells trace back to the American origins of digital culture are now closely mirrored by groups and communities outside the U.S. Once again hacking can be taken as an example. A comparison between the North American communities studied by Coleman, the Dutch ones studied by Turner, and the individuals from all over the world surveyed by Raoul Chiesa and Silvio Ciappi [53], shows that the hacker culture has a global scale, while retaining many characteristics that come from its North American origin. This is the case, in particular, with the libertarian distrust of central authority and faith in individual genius and initiative. In this respect, networking is a powerful means of cultural globalization and "Americanization" [54]. Yet, as is always the case in the study of globalization, detecting a tendency towards standardization is only the first step. It would be far more interesting to identify and compare specific features in the cultural-historical process of adoption of the Internet across different geographical areas and historical periods. The most obvious example is Minitel, a network created by the French postal service in 1978. Born as an electronic phonebook and to provide online services, it soon became a medium for interpersonal communication and a breeding ground for 
online communities (in 1986 it had six millions users). The comparison between this centrally controlled network and the decentralized ARPANET, Usenet or BBSes could help to understand how the management of the network shapes users' agency and community formation, as well as national peculiarities. One less obvious but equally interesting case is that of the "Soviet Internet," studied, from a media history perspective, by Benjamin Peters [55,56].

The fact that geographical proximity is no longer a prerequisite for community interaction does not ultimately limit the importance of geographical provenance with respect to the use of the resource: experiencing a "local" dimension often represents an important factor for Web communities and a crucial incentive for aggregation. Although the role played by face-to-face interactions in shaping online communities has frequently been acknowledged [57], the implications of this on global "digital culture” have yet to be identified.

In her book Always Already New, Lisa Gitelman offers a "media archaeology” [58], drawing a comparison between the adoption of the phonograph (1878-1910) and the spread of digital networking almost a hundred years later. This comparison is meant to downplay the "novelty" of the medium, by viewing it in relation to the phenomena which came before it and the processes that transcend it. Gitelman is interested in the negotiation of the meanings and uses of media technologies, and in particular in the "genealogy of the facticity of the text" in the contemporary age, as well as in the kind of public which the various modes of creation of meaning contribute to engendering.

Much like ARPANET, the phonograph was originally developed by Edison for a very different purpose from that which became prevalent through the creative contribution of manufacturers, distributors and users: within a few years, despite Edison's efforts, what had been conceived as a (professional) device for recording speeches and as a possible replacement for books turned into a means (of entertainment) for the reproduction of music and the "domestication" of sound. Just as the use of the phonograph changed the meaning of the word "record," starting from the 1960s, networking has led to the semantic redefinition of the word "document" by freeing it from its material implications (i.e., its connection to paper). Gitelman describes the Requests for Comments as the first semantically redefined documents: as "a new genre for a new medium": "RFCs are writing that seek to be less written, publications that seek to be less published, and records that might be less than permanent.” ([33], p. 109). The first actors in this process of redefinition were the members of the Network Working Group, the discussion group set up by universities involved in the ARPANET project in order to monitor and manage the development of the network. Chiefly formed by graduate students, this first "recursive public" [59] was to give the tool its distinctive style (an informal, direct, pragmatic and often ironic one), with its roots in colleges and academic research groups. Traces of itI would add-may be found today in the relative informality of electronic communication, at least compared to traditional letters. As temporary work documents, which in their authors' intentions were meant to disappear once the technical aim had been attained, RFCs marked the beginning of the age of ephemeral, non-material texts (and, incidentally, of the related problems which historians must now face). At the same time, they also marked the transformation of the network from a means of data transmission to a means for the circulation of documents. What makes a given electronic text a "document" and distinguishes from other electronic texts (such as code or command strings, headers or menus), as well as from paper ones, is not any material or intrinsic feature it may possess, but simply users' (culturally determined) assessment of the nature of its content. 
The choices and representations of the Network Working Group are merely one element in the cultural genesis of the electronic document and the negotiation of a new meaning of text. The agency of early users reflected and reshuffled the "dominant cultural economy of the late 1960s in the United States": the new electronic text turned into a document within the context of much broader cultural processes. Instead of examining the political culture of the Cold War, like Edwards, or the artistic and political avant-garde, like Gere, Gitelman turns to consider the humanities and the debate on the nature of texts in the 1960s, as reflected by a wide range of phenomena, including disputes on the legal significance of draft cards, polemics surrounding critical editions of literary texts, and Licklider's dream of creating a universal digital library. "The qualities of books as physical bodies formed a subject of public debate and even controversy, and as such they formed one of the cultural sites from within which digital documents and networks would emerge into and partially constitutive of a changeable new media public.” ([33], p. 118).

Gitelman's book shows how important it is for cultural studies of digital networking to examine the agency of users/consumers not just in terms of technological development, but also in relation to the process of negotiation of the meaning of this technology for society as a whole. While Gitelman's argument suffers from the brevity of her book [60], her suggestion to envisage the rise of networking as one phase of the "archaeology of the text" in the contemporary age is of the utmost interest and is worth investigating and extending beyond the earliest electronic documents.

To the best of my knowledge, very few historical and academic studies explicitly discuss specific virtual communities. The most noteworthy exception is Fred Turner's From Counterculture to Cyberculture [61]. Turner explores the influence of American counterculture on online practices, discussed by Castells, and the encounter between this culture and neoliberal views, described by Gere, by focusing on the case study of a specific online community, The Well, and of the main person behind it, Stewart Brand.

With its loathing of technocracy and fear of turning into "cogs" in the (industrial, military, bureaucratic and academic) machine, the communes movement developed the ideal of non-invasive technology. Technological devices and practices could amplify people's potential rather than to control their choices, they could be a means of bringing individuals together rather than of exerting centralized control. Some of the basic features of cyborg discourse (cybernetics, the man-machine symbiosis, the computer as a metaphor for both society and the human mind) were adopted by the "back-to-thelanders" movement as a way of creating a world conceived as the exact opposite of the closed world. In Turner's view, this reinterpretation lies at the origin of the "cyberutopianism" [62,63] that was destined to shape the history of digital networking down to the present day.

Stewart Brand established the Whole Earth Catalogue (WEC) in 1968. The catalog provided a review of technologies and consumer items useful for the rural life of the newly founded communes. Most importantly, it provided a bridge between the counterculture and the new ideas in the fields of cybernetics, system theory and geodesic architecture, as well as a means to link the communes. In Turner's view, the WEC was itself an information technology, a platform foreshadowing online forums and-I would add — even certain forms of contemporary e-commerce: in 1971 many of the reviews were written by readers [64]. In the same year, the WEC was circulating in a million copies, reaching a far wider public than the one it had initially been conceived for, becoming one of the paramount publications for youth counterculture. 
A network of people and communities soon sprang up around Brand and his WEC. With the decline of the movement and the spread of networking technologies, this network migrated online, carrying with it some of the values of the communes, starting from the idea of technology as a means to live the revolution as though it had already taken place by directly applying the ideas of equality, direct democracy, self-fulfillment and personal independence within a well-defined microcosm. In 1985, after actively contributing to the hacker community, Brand established a BBS, The Well (Whole Earth 'Lectronic Link). The significance of this particular platform compared to others created in the early 1980 s is clearly illustrated by Turner: "to its users, the WELL became not simply a computer conferencing system but a way to recreate the countercultural ideal of a shared consciousness in a new 'virtual community'. That community in turn was located on what many WELL users imagined to be the digital descendant of the rural American landscape pioneered by the communards of the 1960s, the 'electronic frontier'. On the WELL, such terms kept alive a New Communalist vision of sociability (...). Ultimately, thanks to the work of the many journalists on the system, and particularly the writings of Howard Rheingold and John Perry Barlow, virtual community and electronic frontier became key frames through which Americans would seek to understand the nature of the emerging public Internet.”([61], p. 143). In its creators' intentions as well as in the minds of its users, the Well was a virtual commune, a space in which the rules of society were given a more egalitarian and anti-hierarchical bent, and where interpersonal barriers were torn down. At the same time, the Well may also be regarded as an experiment in applied cybernetics: through the decentralized control of what was fed into the BBS, the system ran itself and expanded independently of the choices and intentions of its original creators, via direct interaction between the machine and its users. Ultimately, the Well represents one of the first examples of a commercial model (offering to users what other users have created) that was destined to spread on the Internet ten years later and which lies at the basis of the economic success of today's social networks.

Turner further introduced an element which has not yet been discussed, but which is a crucial aspect of the cultural history of digital networking. If the Well acted as a bridge between the counterculture and what Turner describes as "cyberculture," this is also thanks to the role played by successful journalists and popularizers of the technology (Rheingold and Barlow, as already noted in the last quoted passage, as well as Levy and Brand himself). With the commercialization of the Internet in the 1990s, many leading members of the Well started writing for Wired, the magazine which more than any other has promoted and celebrated the utopia of the digital revolution from a markedly libertarian perspective. More generally, journalism has played a central role in the negotiation of various sectors of digital culture. Let us return to the example of hacking. On the one hand, Levy and Raymond's idealized narrative has been taken seriously not just by many academics, but also by many hackers, who base their online conduct on an ethic that is not simply described but actively created and promoted by successful popularizers. On the other, the general media apply the term "hacker" to individuals who do not conform to this ethic. Almost all scholars who have examined the culture of hacking start off by warning their readers that "hacker" is not synonymous with "digital pirate" and that the image fashioned by the media (newspapers, but also films and novels) represents a distortion. But while the first part of this warning is certainly true, the same does not necessarily apply—or no longer applies - to the second. "Digital pirates" ("black hat” or "crackers” in hacker jargon) do indeed exist and see themselves as hackers. In fact, they operate precisely according to a media narrative 
which has defined the hacker as an outlaw of the digital frontier [65]. From a historical and cultural perspective, there is no reason to exclude from "hacker culture" those who fit this description.

Turner's book represents thus far a unique attempt to focus on a specific case study and "real" community (as opposed to virtual) in order to search for the kind of dynamics that other scholars have identified in relation to intellectual thought and digital/Internet/cyber culture. Turner's choice to focus on the Well is perfectly understandable, given the success of some of the members of this group, one of the most influential and prominent communities [66]. This, however, is only the beginning: hopefully, in years to come, other-perhaps equally significant-cases of interaction between counterculture and digital culture will be made an object of scholarly interest. The most obvious case studies that spring to mind are: Abbie Hoffman's Yippies, whose guerilla theatre and interest in media reactions inspired subsequent modes of political protest-from phreakers and hackers down to contemporary "digital direct action"; Community Memory, a terminal that was set up in 1971 as a means for the countercultural community of San Francisco to exchange information, and which arguably constitutes one of the earliest attempts to employ the computer for social networking purposes; Project Xanadu, the first hypertext project, which Ted Nelson, the author of Computer Lib, developed in 1960, also with political aims in mind.

Yet another approach to the complexity of the networks has been adopted by Finn Brunton in a brilliant study by the title of Spam: A Shadow History of the Internet [67]. Instead of focusing on general phenomena or well-defined communities, Brunton examines the specific case of "spam" (undesired or unsolicited electronic messages). In seeking to define what has been regarded as spam across various online communities from 1971 to the present, as well as the countermeasures adopted, Brunton focuses on both the self-descriptions of the groups under scrutiny and spammers' motivations. The book divides the history of spam into three main stages: the first runs from the launching of ARPANET (1971) to the rise of the Internet (1994). The second (1995-2003) witnessed the spread of email advertising and scams, the birth of a genuine spam industry and the introduction of automatic systems of prevention. The third stage which began in 2004, coincides on the one hand with the development of automatic systems for the circulation of email scams (via "botnets") and on the other with the emergence of a kind of spam that is conceived not to be read by people, but to trick search engine algorithms in such a way as to gain visibility.

For the purposes of the present article, what concerns us is Brunton's account of the first stage, spanning the years 1971-1994. Once again, the starting point is found in ARPANET and in particular in RFC706 (1975) "On the Junk Mail Problem"-along with the related discussions in the MSGGROUP newsletter. "Improper" uses of the military/academic network (e.g., to celebrate social events, discuss sci-fi literature, send anti-war messages or riddles) were rather frequent and informally tolerated. The first message to be perceived as spam arrived in 1978, in the form of an advertisement for DEC (one of the leading hardware companies at the time). "This message exposed the rift within the concept of "community" on the network. It is the split between community as communication for the sake of shared interests, (...) an institutional structure with its sociological roots in the Gesellschaft, and the community of 'relationships and values' of Gemeinschaft” ([68], p. 31). Brunton stresses the desire of ARPANET users to keep their distance from "brass and bureaucrats" and to independently define the standards for network messages, based on the mutual trust between the members of a group that is small but potentially open to anyone with the necessary technical know-how. What we have 
here, then, is a kind of performative ontology that-in Brunton's words_- "shaped the production of email and social computing generally” ([67], p. 26).

Within their small ranks, ARPANET users could explicitly discuss the issue of spam and of the detection and possible punishment of those infringing the informal ethic of the group. The same was not the case with Usenet, a network that while nowhere close to the present-day Internet in terms of numbers, nonetheless soon became global, with the establishment of thousands of "communities" divided into interest groups. Brunton identifies various different stances with regard to undesired messages, all of which reflect the same dominant reaction. The latter is examined in relation to two specific cases: a chain-letter scam (1988) and one of the first electronic advertising messages to enjoy vast circulation, the greencard lottery message (1994). As Usenet users' main concern was to keep the powers that be out of the network and its governance, in both cases they reacted through the online equivalent of charivari-the practice of public and collective symbolic humiliation in response to what are perceived as individual transgressions according to traditional mores. In its digital incarnation, charivari is "the assertion of a different kind of politics, in which the network's population at large participates directly through jokes, pranks, verbal abuse, public shame, and privacy-violating crowdsourced surveillance, rather than through the mediation of sysadmins (system administrators), legislators, or police officers" ([67], p. 46). As in the case of charivari, the frontiers between public and private here become blurred (once the original senders of the message had been traced, users would divulge their address and phone number); and through mockery and joint efforts the limits of what is permissible are temporarily extended (the sender would be made the object of spam, telephone pranks and insults). As with charivari, this is a symbolic and instinctual revolt, with no political outcome or motivation, in response to the perceived breach of the unwritten rules of a community. Brunton rightly notes that this practice is widespread in contemporary online communities, one example being the notorious 4chan forum, out of which the group of cyberactivists and pranksters “Anonymous” emerged after a charivari against the Church of Scientology [65].

In examining the differences between the 1988 message and the 1994 one, the author emphasizes how the increase in the number of users deeply changed the communities and their reaction to spam: while in the former case the charivari successfully stopped the spammer, the message offering legal assistance for obtaining a green card continued to be sent, even though in 1994 a far larger number of people could participate in the charivari. By then, Usenet membership was no longer limited to academics or technology enthusiasts - relatively homogeneous groups sharing a specific approach to the tool and the same community ethic. On the one hand, the commercial spread of digital networking had introduced a different public, one unfamiliar with the previous ethic and open to commercial offers, or at any rate no longer as resolute in punishing those failing to abide by the rules; on the other hand, it had opened the gate to the powers that be, who at the time were placing no restrictions on undesired commercial offers on the network, thereby indirectly authorizing forms of behavior deemed unacceptable by the original community. Over time, this led to the adoption of a system of automatic filters analogous to the one found in all email accounts nowadays: a "technolibertarian" solution, according to Brunton, since it safeguarded both spamming freedom and the freedom to avoid spam through the creation of optional blocks for each user.

Despite having been published by the prestigious MIT Press, just like the books by Edwards, Abbate and many other scholars mentioned in the present article, so far Spam has not been met with the same academic success — at least, judging from the limited number of reviews currently found on 
JSTOR or Google Scholar. As far as I can tell, none of these reviews has been published in a history journal. While this is no doubt at least partly due to the fact that it is a recent publication, one may also blame its rather obscure subtitle, intended to grab the attention of a wider public than that of historians, as well as the fact that the latter might not regard spam as a phenomenon worth investigating. Yet, Brunton's book represents a crucial contribution to the cultural history of digital networking. And this, not simply because it discusses a topic the "online attention market," which is central to this field of study, but also because it is one of the few works (along with Gitelman's book) to openly engage with the new sources and consider which methods to adopt in order to face the challenges they raise. The real subject of Brunton's book-or, at any rate, of its first section-is not spam or spammers, but the communities that frowned upon the practice: “(Spam) forces the question: what, precisely, are we doing here that spam is not, such that we need to restrain and punish it? (...) (it) demands higher-order debate from the social spaces in which it operates.” ([67], p. 15). Faced with the aforementioned difficulty of defining the boundaries of a given online community and of using it to draw implications about other communities, Brunton chose to focus not on what communities claimed to be, but on what they unanimously forbade their members from doing and on their modes of preventing and punishing transgressions. Spam-undesired messages in an age in which the costs of online connection were high and computer memory very limited - thus serve as a negative way of setting the boundaries of a community, as means of defining its positive values by viewing them against a negative backdrop (Shadow History). At the same time, in comparing online behavior to well-established cultural practices such as charivari, Brunton "trivializes" the phenomenon of digital networking - in the positive sense of the term defined by Jonathan Sterne-by relating it to the flow of "economics, ideology, everyday life, and experience” ([2], p. 99), thereby enabling its investigation in connection with themes and resources more familiar to cultural history and cultural studies.

\section{Conclusions}

"Cyberspace. A consensual hallucination experienced daily by billions of legitimate operators, in every nation, by children being taught mathematical concepts...A graphic representation of data abstracted from the banks of every computer in the human system. Unthinkable complexity. Lines of light ranged in the nonspace of the mind, clusters and constellations of data" [68].

When, in 1984, sci-fi novelist William Gibson invented the term "cyberspace," he likely did not expect it would become a popular academic metaphor, and that his lines would be an almost unavoidable quote in every essay on the topic (this one included). If the geographical metaphor has been so often used, this is probably due to the fact that it gave "materiality" to a field of study, opening it up to the tools traditionally used to analyze geographically located phenomena. Even more important, it offered the possibility to name a subject of study (cyberspace) and to gather different disciplines around it. A phenomenon happening in the "nonspace of the mind," an interaction with no physical presence, was made thinkable through an artificial "spatialisation.” Gibson's characterization of this space as too vast to be understood in its entirety was quite naturally (and legitimately) forgotten. Still, many of the problems discussed in the first part of this article arise at the margins of this ideal-type, when the "unthinkable complexity" of a medium that can be bent to almost every use and touches today virtually every aspect of social reality can no longer be ignored. The studies discussed in the second part of this essay can be read as attempts to make this complexity "thinkable" in cultural terms, 
either by linking the digital interconnectivity to better known social and historical phenomena or by applying the traditional tools of cultural research to a new kind of human aggregate. All the studies I quoted and summarized highlight the necessity of dissecting cyberspace in order to create a meaningful narrative, as well as the variety of methods and themes that can be used to make sense of its complexity. General reconstructions of the development of the medium, while recognizing the importance of the end user, focused for the most part on the more accessible role of "institutional cultures” in shaping interconnectivity. The Foucauldian studies conducted by Edwards and Gere try, successfully, to link phenomena as diverse as Cold War rhetoric, computer art and sci-fi movies in a dominant "cyborg discourse" or "digital culture." Few experimental works take on the challenge of studying the end users. Turner's book takes full advantage of the celebrity and publicity of the Well in order to create a case study that is, to my knowledge, the first historical exploration into the uncharted territory of virtual communities. Gitelman's and Brunton's books, on the other hand, limit the complexity of cyberspace by focusing not on a single group but on a single phenomenon. Their attempts represent, in my opinion, the most daring excursions to date into the field of cultural history of interconnectivity: recognizing the intrinsic novelty of the problems posed by cyberspace, they discuss openly how the methodological tools and historical expectations have to change in order to meet the new challenge. Whereas Gitelman focuses on the problem of the evolution of the idea of text in the digital era-and, consequently, the problem of the immateriality of the sources-Brunton focuses on the definition of values and identity boundaries inside virtual communities.

What emerges from the comparison of all these studies is the lack of a shared terminology, essentially due to the fact that digital interconnectivity is not yet a legitimate historical-cultural field of study and the methodological debate on the topic is virtually nonexistent among historians. Internet culture, digital culture, cyber-culture, culture of connectivity: cyberspace may be a hallucination, as Gibson imagined, but surely it is not consensual, at least from an academic point of view. Inevitably digital connectivity as an organic whole remains unthinkable: its epistemological value resides in what it suggests, not in what it explains. But the same thing could be said of other macro-categories (such as "culture," for example) that have to be continually redefined according to the particular aspect being studied-or be left to the intuition of the reader.

If it is true, as Manuel Castells wrote, that "the social world of the Net is as diverse, and contradictory, as society is," it may very well be that the "fragmented" approach presented in these pages is the only way to penetrate it, and that cultural history, with its propensity for multiple approaches and its loose methodological bindings, is, after all, well suited to the task.

\section{Acknowledgments}

A sincere thank you to Carlotta Sorba and Enrico Francia, who read this piece and enriched it with their suggestions and insights.

\section{Conflicts of Interest}

The author declares no conflict of interest. 


\section{References and Notes}

1. Marc A. Smith, and Peter Kollock, eds. Communities in Cyberspace. London and New York: Routledge, 1999, p. 195.

2. David Bell, ed. Cybercultures: Critical Concepts in Media and Cultural Studies. London and New York: Routledge, 2006.

3. Tommaso Detti, and Giuseppe Lauricella. Le Origini di Internet. Milano: Bruno Mondadori, 2013, p. 85.

4. Nelly Oudshoorn, and Trevor Pinch, eds. How Users Matter: The Co-Construction of Users and Technology. London and Cambridge: MIT Press, 2005.

5. Christopher Cumo. Science and Technology in 20th Century American Life. Westport: Greenwood Press, 2007, p. 75.

6. Kristen Haring. Ham Radio’s Technical Culture. Cambridge: MIT Press, 2007.

7. I am alluding here to the practice known as "phreaking”, which developed in the United States at the end of the 1960s. "Phreakers" would, often illegally, access the phone network in order to test its limits and prove their skills to a hobbyist community.

8. Eric A. Von Hippel. "Lead Users: A Source of Novel Product Concepts.” Management Science 32 (1986): 791-805.

9. Mark Zuckerberg. “Our fist 100 millions.” Available online: https://www.facebook.com/notes/ facebook/our-first-100-million/28111272130 (accessed on 1 March 2014).

10. Facebook. "Newsroom-Company Info.” Available online: http://newsroom.fb.com/companyinfo/ (accessed on 16 April 2014).

11. The monopoly that Google and a few other companies exercise on the Internet today, in all its various aspects, would certainly make this a rather bold claim. For a historical overview of the nature of this control, see Jose van Dijck. The Culture of Connectivity. Oxford: Oxford University Press, 2013.

12. Geert Lovink. Zero Comments: Blogging and Critical Internet Culture. New York: Routledge, 2008, p. IX.

13. It would be more accurate to describe this, in more general terms, as the "collaborative software development model” or F/OSS (Free and Open Source Software). The practice consists in offering software code to anyone interested, so that it may be improved upon, corrected or used in ways that were never foreseen by the original programmers. Although the Open Source movement was officially born in the mid-1990s, the practice is one of the few characteristics shared by all hacker communities since the 1960s. On the origins of Open Source, see Steve Weber. The Success of Open Source. Cambridge: Harvard University Press, 2004, pp. 20-53.

14. Eric S. Raymond. The Cathedral and the Bazaar: Musings on Linux and Open Source by an Accidental Revolutionary. Cambridge, MA: O’Reilly, 2001, p. 30.

15. On the economic and cultural implications of the spread of open source see Marleen Wynants, and Jan Cornelis, eds. How Open Is the Future?: Economic, Social \& Cultural Scenarios Inspired by Free \& Open-Source Software. Brussels: VUB Brussels University Press, 2005.

16. “World Wide Web.” Available online: http://info.cern.ch/hypertext/WWW/TheProject.html (accessed on 1 March 2014). Note how even this document, kept online by CERN as historical 
evidence, bears witness to the "collaborative development model" that shaped the history of digital interconnectivity (links "How can I help” and “Getting Code”).

17. Paul S. Piper. "Research on the Internet." In The Internet Encyclopedia. Edited by Hossein Bidgoli. Hoboken: John Wiley \& Sons, 2004, vol. 3, p. 202.

18. Johnny Ryan. A History of the Internet and the Digital Future. London: Reaktion Books, 2010, pp. 137-50.

19. Geert Lovink sets the end of Web 1.0 in the early 2000s, with the burst of the Dot-Com bubble. The term Web 2.0 became popular in 2004, after a conference organised by Tim O’Reilly. The proceedings of the conference are summed by Tim O’Reilly in "What is Web 2.0." Available online: http://oreilly.com/pub/a/web2/archive/what-is-web-20.html?page=1 (accessed on 1 March 2014).

20. "Giving a history of the World Wide Web, the initial code for which was written in 1990, will be much more difficult than writing about the early days of computing. Historians avoid writing about the recent past for good reasons. What would readers think of a history that ended with a statement that the culmination of all computing history was Gopher?” (Gopher is the first rudimentary search engine). Paul E. Ceruzzi. A History of Modern Computing. Cambridge: MIT Press, 2003, p. 301.

21. Pekka Himanen. The Hacker Ethic, and the Spirit of the Information Age. New York: Random House, 2001.

22. Steven Levy. Hackers: Heroes of the Computer Revolution. Garden City: Anchor Press/Doubleday, 1984.

23. On the meaning of the word "hack", which is still a matter of debate in hacker communities, see Sherry Turkle. The Second Self: Computers and the Human Spirit, 20th Anniversary Ed. Cambridge: MIT Press, 2005, pp. 207-08.

24. Paul A. Taylor. Hackers: Crime in the Digital Sublime. London and New York: Routledge, 1999, pp. 13-23.

25. These considerations are drawn from my ongoing research on the subculture of phreaking and the phreaker newsletter "Youth International Party Line” (YIPL-later Technological American Party and Technological Assistance Program-TAP), founded by Abbie Hoffman in 1968.

26. Claude S. Fischer. Made in America: A Social History of American Culture and Character. London and Chicago: The University of Chicago Press, 2010, pp. 10-12, 95-160.

27. Andrew Ross. Strange Weather: Culture, Science, and Technology in the Age of Limits. London and New York: Verso, 1991, pp. 75-100.

28. Consider the pioneering essays by Roy Rosenzweig, collected in Roy Rosenzweig. Clio Wired: The Future of the Past in the Digital Age. New York: Columbia University Press, 2011.

29. Google Groups. Available online: https://groups.google.com. (accessed on 1 March 2014).

30. The Usenet Archive. Available online: http://www.theusenetarchive.com/ (accessed on 1 March 2014). The data are drawn from an email exchange between Mr. Stadler and myself in February 2014.

31. For some preliminary considerations regarding the historical investigation of Usenet (based on quantitative analysis), see Ian Milligan. "Exploring the Usenet Archive: Early Thoughts." Available online: http://ianmilligan.ca/2013/03/06/exploring-the-usenet-archive-early-thoughts (accessed on 1 March 2014). 
32. For a short history of the development of Usenet see Michael Hauben, and Ronda Hauben. Netizens: On the History and Impact of Usenet and the Internet. Los Alamitos: IEEE Computer Society Press, 1997, pp. 35-47.

33. Lisa Gitelman. Always Already New: Media, History and the Data of Culture. London and Cambridge: MIT Press, 2008, p. 130.

34. Yet not in all cases. For example, the website Europeana (founded by the European Commission for the online display of historical and artistic artifacts from EU museums and archives) is promoting the digitization of privately owned sources related to the Great War across Europe. The digital version of these sources is available at http://www.europeana1914-1918.eu (accessed on 1 March 2014), but the originals are still in the hands of the owners, and hence unavailable to researchers and scholars.

35. Steve Jones. "Studying the Net. Intricacies and Issues." In Doing Internet Research: Critical Issues and Methods for Examining the Net. Edited by Steve Jones. Thousand Oaks: Sage Publications, 1999, pp. 1-28.

36. Wiebe E. Bijker, Thomas P. Hughes, and Trevor J. Pinch, eds. The Social Construction of Technological Systems: New Directions in the Sociology and History of Technology. Cambridge: MIT Press, 1987.

37. Wiebe E. Bijker, and John Law. Shaping Technology/Building Society: Studies in Sociotechnical Change. Cambridge: MIT Press, 1992.

38. Constance Penley, and Andrew Ross. Technoculture. Minneapolis: University of Minnesota Press, 1991.

39. Janet Abbate. Inventing the Internet. Cambridge: MIT Press, 2000, pp. 3-4.

40. Marcel C. LaFollette. Making Science Our Own: Public Images of Science, 1910-1955. Chicago: University of Chicago Press, 1990, p. 14.

41. Thomas P. Hughes. Rescuing Prometheus. New York: Pantheon Books, 2000, p. 297.

42. Manuel Castells. The Internet Galaxy: Reflections on the Internet, Business, and Society. Oxford and New York: Oxford University Press, 2001, pp. 33-58.

43. On the Internet as gift economy, see Tiziana Terranova. "Free Labor: Producing Culture for the Digital Economy.” Social Text 63 (2000): 33-58.

44. Gabriella Coleman. Coding Freedom: The Ethics and Aesthetics of Hacking. Princeton: Princeton University Press, 2013.

45. Thomas Douglas. Hacker Culture. Minneapolis: University of Minnesota Press, 2002.

46. The similarities between the hacker style of communication and jargon and the "informal", often ironic, aggressive or irreverent style of many online communities is clear to anyone who has studied the former and participated in the latter. This connection is not explored in Castells' book — which has different aims — and, as far as I know, has never been studied in depth.

47. Some exceptions are mentioned below—-particularly Fred Turner's study.

48. Manuel Castells. The Rise of the Network Society. Malden: Blackwell Publishers, 1996, p. 385.

49. Geert Lovink. Dynamics of Critical Internet Culture. Amsterdam: Institute of Network Cultures, 2009, pp. 31-34.

50. Paul N. Edwards. The Closed World: Computers and the Politics of Discourse in Cold War America. Cambridge: MIT Press, 1997, p. XIII. 
51. The concept of "technowar" was coined—in relation to the Vietnam War-by James William Gibson in a book that provides an important premise for Edwards' work: James William Gibson. The Perfect War: Technowar in Vietnam. Boston: Atlantic Monthly Press, 1986.

52. Charlie Gere. Digital Culture. London: Reaktion Books, 2002, pp. 15-16.

53. Raoul Chiesa, and Silvio Ciappi. Profiling Hackers: The Science of Criminal Profiling as Applied to the World of Hacking. Boca Raton: Auerbach Publications, 2009.

54. Martin Dodge, and Rob Kitchin. Mapping Cyberspace. London and New York: Routledge, 2003, pp. 32-51.

55. Benjamin Peters. "From Cybernetics to Cyber Networks: Norbert Wiener, the Soviet Internet, and the Cold War Dawn of Information Universalism.” Ph.D. Thesis, Columbia University, May 2010.

56. Benjamin Peters. The Soviet Internet: How Not to Network a Nation. Cambridge: The MIT Press, 2015, forthcoming.

57. For a critical review of the sociological studies on the matter see Andrea Miconi. "The Web in everyday life. Or, how the Internet became an household appliance.” Snodi. Pubblici e privati nella storia contemporanea 11 (2013): 43-60.

58. "Media archaeology is first and foremost a methodology, a hermeneutic reading of the 'new' against the grain of the past, rather than a telling of the histories of technologies from past to present.” Geert Lovink. My First Recession. Rotterdam: NAi Publishers/V2-Organization, 2003, p. 11, cited and discussed in ([30], p. 11).

59. "A recursive public is a public that is vitally concerned with the material and practical maintenance and modification of the technical, legal, practical, and conceptual means of its own existence as a public; it is a collective independent of other forms of constituted power and is capable of speaking to existing forms of power through the production of actually existing alternatives.” Christopher Kelty. Two Bits: The Cultural Significance of Free Software. Durham: Duke University Press, 2008, p. 3. This well-known definition applies to many contemporary virtual communities, from hacker groups to Wikipedia contributors, from Flickr users ([11], pp. 89-106) to activists of the Electronic Frontier Foundation.

60. The first part of the book is discussed in more depth in Lisa Gitelman, and Geoffrey B. Pingree. New Media, 1740-1915. Cambridge: MIT Press, 2003; the second is the object of a forthcoming publication, according to the author's website: http://lisagitelman.org/bio/ (accessed on 1 March 2014).

61. Fred Turner. From Counterculture to Cyberculture: Stewart Brand, the Whole Earth Network, and the Rise of Digital Utopianism. Chicago: University of Chicago Press, 2006.

62. On the hopes of social, political and personal renewal raised by the medium, see Karen Pärna. Believing in the Net: Implicit Religion and the Internet Hype, 1994-2001. Leiden: Leiden University Press, 2010.

63. For a criticism of these same hopes, expressed at the height of the Dot-Com bubble, see Robert McChesney. "So much for the Magic of Technology and the Free Market." In The World Wide Web and Contemporary Cultural Theory. Edited by Andrew Herman and Thomas Swiss. New York: Routledge, 2000, pp. 5-36.

64. "(Brand) invited the reader to become a producer of economic value, a contributor to a textual community, and still a buyer of the Catalog” (p. 90). This statement perfectly applies to the evaluation and advertisement model heralded by Amazon, even though Turner does not actually 
mention the company. Yubo Chen, and Jinhong Xie. "Online Consumer Review: Word-of-Mouth as a New Element of Marketing Communication Mix.” Management Science 54 (2008): 477-91.

65. A recent and striking case of hackers who do not follow the "hacker ethic" described by Levy and others, but embrace the media definition of hacking, can be found in the origins of Anonymous: Gabriella Coleman. "Our Weirdness is free." Triple Canopy, 2012. Available online: http://canopycanopycanopy.com/issues/15/contents/our_weirdness_is_free (accessed on 1 March 2014).

66. The successful critic and popularizer Howard Rheingold is credited to have coined the expression "virtual community". John Perry Barlow was among the founders of the Electronic Frontier Foundation, one of the world's most important associations for digital rights. Wired, the offspring of the Well on the Internet, is the now the leading magazine-in both in its electronic and paper format — for the promotion of and comment on digital technology.

67. Finn Brunton. Spam: A Shadow History of the Internet. Cambridge: MIT Press, 2013.

68. William Gibson. Neuromancer. London: Grafton, 1984, p. 67.

(C) 2014 by the authors; licensee MDPI, Basel, Switzerland. This article is an open access article distributed under the terms and conditions of the Creative Commons Attribution license (http://creativecommons.org/licenses/by/3.0/). 